\title{
Importance of miR-299-5p in colorectal cancer
}

\author{
Alavieh Fateh, Mohammad Ali Hosseinpour Feizi, Reza Safaralizadeh, Shirin Azarbarzin \\ University of Tabriz, Tabriz, Iran
}

Abstract

Background MicroRNAs (miRNAs) are effective regulators of gene expression that play a pivotal role in the pathogenesis of colorectal cancer (CRC) and various other cancers. The high prevalence of aberrant miRNA expression in CRC suggests that they can be used as biomarkers and anticancer molecules for therapeutic purposes. There is evidence that microRNA-299-5p (miR-299-5p) is associated with vital cell processes (e.g. epithelial-mesenchymal transition, proliferation, and tumorigenicity) and its improper expression with tumorigenesis in many types of human cancer. This prospective study investigated the contribution of miR-299-5p to CRC tumorigenesis.

Methods The real-time reverse transcription-polymerase chain reaction was used to examine miR-299-5p expression levels prospectively in 40 sample pairs of CRC tissue and adjacent noncancerous tissue ( $>2 \mathrm{~cm}$ from cancer tissue). The ability of miR-299-5p to function as a tumor marker was also examined.

Results The expression levels of miR-299-5p were significantly downregulated in the group of CRC samples compared with matched noncancerous tissue samples. No significant relationship was found between miR-299-5p expression levels and clinicopathological features. Receiver operating characteristic analysis gave an area under the curve of $71 \%$ for miR-299-5p with $68 \%$ sensitivity and $78 \%$ specificity $(\mathrm{P}=0.001)$.

Conclusion The miRNA miR-299-5p may be considered as a tumor marker in CRC and could be of assistance as a potential predictive biomarker in the diagnosis of this cancer.

Keywords Colorectal cancer, biomarker, microRNA, miR-299-5p

Ann Gastroenterol 2017; 30 (3): 1-5

\section{Introduction}

Colorectal cancer (CRC) is considered to be the third most common cause of cancer-related death [1], accounting for $10 \%$ of the worldwide cancer incidence and mortality [2]. More specifically, it is recognized as the second and third most frequently diagnosed type of cancer in females and males, respectively [3]. It has been one of the prevalent cancers in western populations [4]; a low rate of this type of cancer has been observed in Asia, Africa, and South America [5]. Unfortunately, in developing countries and most Asian countries, its yearly incidence is expected to increase over the next two decades [6]. Recently conducted studies in an

Department of Animal Biology, Faculty of Natural Science, University of Tabriz, Tabriz, Iran

Conflict of Interest: None

Correspondence to: Mohammad Ali Hosseinpour Feizi, Tel: +98 41 33362280, Fax: +98 41 33362282, e-mail: pourfeizi@eastp.ir

Received 07 January 2016; accepted 07 February 2017; published online 28 March 2017

DOI: https://doi.org/10.20524/aog.2017.0139
Iranian context are indicative of a rapidly increasing incidence of this type of cancer [7]. In this regard, a remarkable incidence of cancer occurring in the gastrointestinal tract has been discerned in East Azerbaijan, which is located in the north west of Iran and has a recently reported population of $3,724,620$, comprising $50.5 \%$ males $(1,882,031)$ and $49.5 \%$ females $(1,842,589)$ [8]. Thus, knowing more about the biology of CRC could be very useful for designing effective prognostic, diagnostic, and therapeutic plans to help decrease the impact of this disease [9].

MicroRNAs (miRNAs) are small, non-coding RNA molecules (about 18-25 nucleotides in length) first discovered in the early 1990s in Caenorhabditis elegans [10]. They are the largest family of noncoding RNAs and are believed to regulate up to one third of all genes [11]. There is increasing evidence that miRNAs can function as tumor suppressors or oncogenes [12]. They can be used as biomarkers in diagnosing the progression of several cancers [13]. Several studies have revealed that the microRNA expression patterns found in CRC show frequent abnormalities in this malignancy [14].

MiR-299-5p is located in the imprinted Dlk1-Dio3 region on chromosome 14q32.31 [13]. The aforementioned cluster resides within the region of a parentally imprinted chromosome [15] 
and has been reported to be downregulated in ovarian cancer [16]. It is also involved in gastrointestinal stromal tumors and adenocarcinoma [17], melanoma [18], ependymoma [19], neuroblastoma [20], and osteosarcoma [21]. The importance of miR-299 in CRC and its variations have been reported previously [22]. This area is a great developmental region; it accompanies several phenotypes associated with the changes in the dosage of the genes within this region in humans and mice [23].

\section{Patients and methods}

\section{Study population}

Between November 2014 and June 2015, a total of 40 CRC samples and normal adjacent tissues were collected from 40 patients diagnosed with CRC following colonoscopy and sigmoidoscopy at Imam Reza Hospital (Tabriz, Iran), the first affiliated hospital of Tabriz University of Medical Sciences. None of the patients had undergone chemotherapy or radiotherapy, or any adjuvant therapy.

A section of the resected specimen at the farthest tumor distance was used to obtain the non-tumor counterparts $(>2 \mathrm{~cm}$ from tumor). All study members were born in East Azerbaijan, Iran. The Research Ethics Committee of Imam Reza Hospital approved the present study, carried out in accordance with our institutional protocol; informed consent was obtained from all patients. Resected specimens were analyzed by standard histopathological examination and colorectal adenocarcinoma was selected for investigation.

\section{Sample preparation and RNA isolation}

In this study, all the tissue samples were freshly frozen at $-80^{\circ} \mathrm{C}$ until RNA extraction. Total RNA was isolated using the TRIzol reagent (Invitrogen Carlsbad, CA) which was applied according to the manufacturer's instructions. Briefly, tissue samples were homogenized with $1 \mathrm{~mL}$ TRIzol LS and incubated for $5 \mathrm{~min}$ at room temperature. Next, $200 \mu \mathrm{L}$ chloroform was added, shaken vigorously for $15 \mathrm{sec}$, and incubated for 2-15 $\mathrm{min}$ at room temperature. Centrifugation was then applied at $12,000 \mathrm{rpm}$ for $15 \mathrm{~min}$ at $4^{\circ} \mathrm{C}$. After the aqueous phase had been transferred into a new Eppendorf tube, $500 \mu \mathrm{L}$ of $100 \%$ isopropanol was added. The mixture was stored at $20^{\circ} \mathrm{C}$ overnight, followed by a $13,000 \mathrm{rpm}$ centrifugation for $10 \mathrm{~min}$ at $4^{\circ} \mathrm{C}$, pelleting the nucleic acid. After removal of the supernatant, $1 \mathrm{~mL}$ of $75 \%$ ethanol was added to wash the RNA pellet. The sample was then centrifuged at $7500 \mathrm{rpm}$ for $5 \mathrm{~min}$ at $4^{\circ} \mathrm{C}$, after which $25 \mu \mathrm{L}$ RNase-free water was added to the RNA pellet, which was finally incubated in a water bath at $55-60^{\circ} \mathrm{C}$ for $10-15 \mathrm{~min}$. PicoDrop 2000 (Bob Batty International, UK) was used to quantify the concentration of isolated RNA. The extracted RNAs were stored at $-80^{\circ} \mathrm{C}$ until cDNA synthesis. Subsequently, a $10 \mu \mathrm{L}$ DNase I treatment reaction (Fermentas, Canada) was performed to deteriorate any DNA contaminations in the extracted RNAs.

\section{Reverse transcription and quantitative real-time polymerase chain reaction (PCR)}

To perform reverse transcription, $120 \mathrm{ng}$ of total RNA in a final volume of $10 \mu \mathrm{L}$ reaction mixture was utilized. The $10 \mu \mathrm{L}$ RT reaction mixture was incubated at $37^{\circ} \mathrm{C}$ for $60 \mathrm{~min}$ and at $85^{\circ} \mathrm{C}$ for $5 \mathrm{sec}$; then the mixture was held at $4^{\circ} \mathrm{C}$ using the Prime Script(R)miRNA cDNA Synthesis Kit (ParsGenome, Iran). Finally, $90 \mu \mathrm{L}$ of the RNase-free water was added to dilute the RT product.

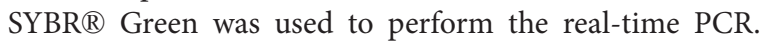
MiR-299-5p and 5s rRNA (as a control RNA) primers were also purchased from ParsGenome. All PCR reactions, including non-template controls, were run in triplicate using a Rotor-Gene Q - QIAGEN Real-time PCR Detection System. REST2009 Software was employed to analyze the raw data obtained. Analyses of all the samples were performed in triplicate. The cycle number in which the fluorescence passed the fixed threshold was regarded as the definition of the threshold cycle (Ct). One control sample without any templates was added to each experiment. Polyacrylamide gel electrophoresis confirmed the ultimate real-time PCR products.

\section{Normalization and data analysis}

To apply normalization, the housekeeping reference gene, 5srRNA, and adjacent non-tumor tissue were used as a calibrator to present more accurate quantification of mRNA levels. The relative expression of miR-299-5p was analyzed using a randomization test with the Relative Expression Software Tool (REST) 2009 (http://gene-quantification.com/rest-2009. html) and REST was using the $2^{-\Delta \Delta C t}$ method to examine the miR-299-5p expression levels in the CRC tissues relative to their matched non-tumor counterparts. The following step was the determination of the $\mathrm{Ct}$ of fluorescence for each of the samples. The $\Delta \mathrm{Ct}$ values $(\Delta \mathrm{Ct}=\mathrm{Ct}$ miR-299-5p - Ct $5 \mathrm{~s})$ were indicative of the presence of differences in the expression levels between miR-299-5P and 5s rRNA. Moreover, $\Delta \Delta \mathrm{Ct}$ revealed differences between cancer tissue and the matched control in terms of the $\Delta \mathrm{Ct}$ values $(\Delta \Delta \mathrm{Ct}=\Delta \mathrm{Ct}$ cancer $-\Delta \mathrm{Ct}$ control $)$. In addition, the $2^{-\Delta \Delta \mathrm{Ct}}$ value (fold value) was determined. It was found that when the fold value was $<1$, a fold change $<1$ in the expression was defined as decreased expression.

\section{Statistical analysis}

SPSS 18.0 software (Chicago, IL, USA) was used to analyze the obtained results, with a two-sided P-value $<0.05$ considered as the criterion for statistical significance. Receiver operating characteristic (ROC) analysis was used to evaluate the 
specificity and sensitivity of miR-299-5p expression levels in discriminating between CRC and normal tissue. The sensitivity and specificity at various cutoff values were calculated using Sigma Plot 12.5. P-values $<0.05$ were regarded as indicative of a statistically significant result.

\section{Results}

\section{Expression levels of miR-299-5p in CRC and normal tissues}

To compare the level of miR-299-5p expression in CRC in relation to normal tissue, the researchers entered the Ct values of all the samples into the REST 2009 software. The results of the randomization test displayed that miR-299-5p expression in tumor samples decreased 5.4 times more than in normal tissue (Fig. 1).

\section{The association between the expression of miR-299-5p} and clinicopathological features

As Table 1 shows, as regards clinicopathological characteristics, no significant relationship was detected between miR-299-5p expression and sex $(\mathrm{P}=0.837)$, age $(\mathrm{P}=0.839)$, tumor location $(\mathrm{P}=0.580)$, or histological grade $(\mathrm{P}=0.705)$.

Table 1 The relationship between clinicopathological features and $\underline{\text { miR-299-5p expression levels in tissue samples with colorectal cancer }}$

\begin{tabular}{|c|c|c|c|}
\hline Variable & $\mathrm{n}$ & $\begin{array}{c}\text { miR-299-5p } \\
\text { relevant expression } \\
\left(2^{\Delta \Delta C t}\right)\end{array}$ & $\mathrm{P}$-value \\
\hline Sex & & & 0.84 \\
\hline Male & 18 & $20.7422 \pm 2.82253$ & \\
\hline Female & 22 & $20.0500 \pm 4.95217$ & \\
\hline Age & & & 0.84 \\
\hline$<60$ & 17 & $21.5194 \pm 3.13913$ & \\
\hline$>60$ & 23 & $19.5057 \pm 4.56207$ & \\
\hline Tumor location & & & 0.58 \\
\hline Colon & 16 & $21.0250 \pm 2.96277$ & \\
\hline Sigmoid & 12 & $21.1400 \pm 3.94373$ & \\
\hline Rectum & 12 & $18.7175 \pm 5.38990$ & \\
\hline Histological grade & & & 0.71 \\
\hline Well differentiated & 19 & $20.4900 \pm 4.71310$ & \\
\hline $\begin{array}{l}\text { Moderately } \\
\text { differentiated }\end{array}$ & 17 & $20.4476 \pm 3.55513$ & \\
\hline $\begin{array}{l}\text { Poorly } \\
\text { differentiated }\end{array}$ & 4 & $19.3850 \pm 4.03584$ & \\
\hline
\end{tabular}

Data are presented as mean \pm SD; P-values were obtained using analysis of variance (ANOVA). No significant relationship was observed between miR-299-5p expression levels and clinicopathological characteristics

\section{Ability of miR-299-5p to function as a CRC tumor marker}

In the ROC analysis, the level of expression of miR-299-5p yielded an area under the curve of $71 \%$, with $68 \%$ sensitivity and $78 \%$ specificity for the identification of CRC tumor samples ( $\mathrm{P}=0.001)$. Consequently, miR-299-5p expression can be considered as a tumor marker (Fig. 2).

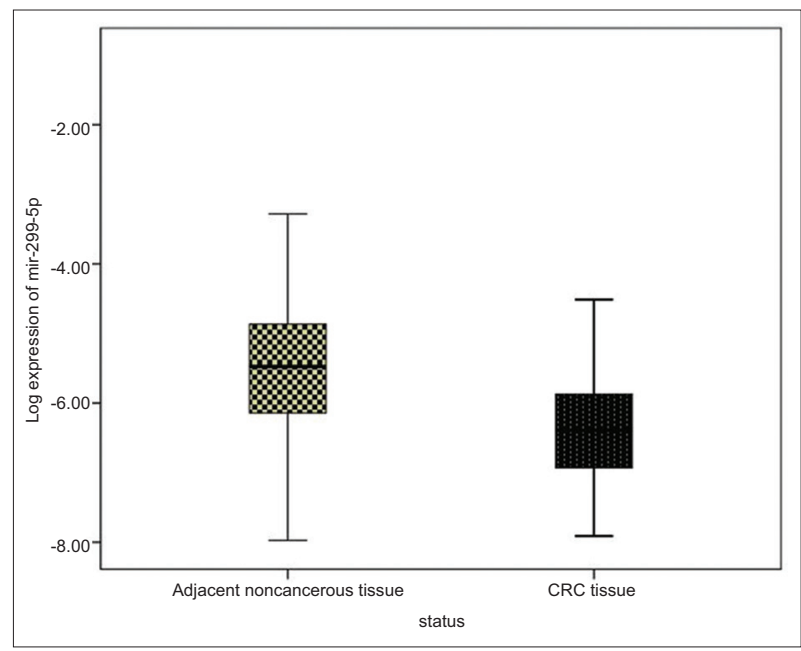

Figure 1 Figure 1 Disparate expression of miR-299-5p in tumor samples, showing a significantly lower value (4.7 times to 5.4 ) compared to normal samples.

CRC, colorectal cancer

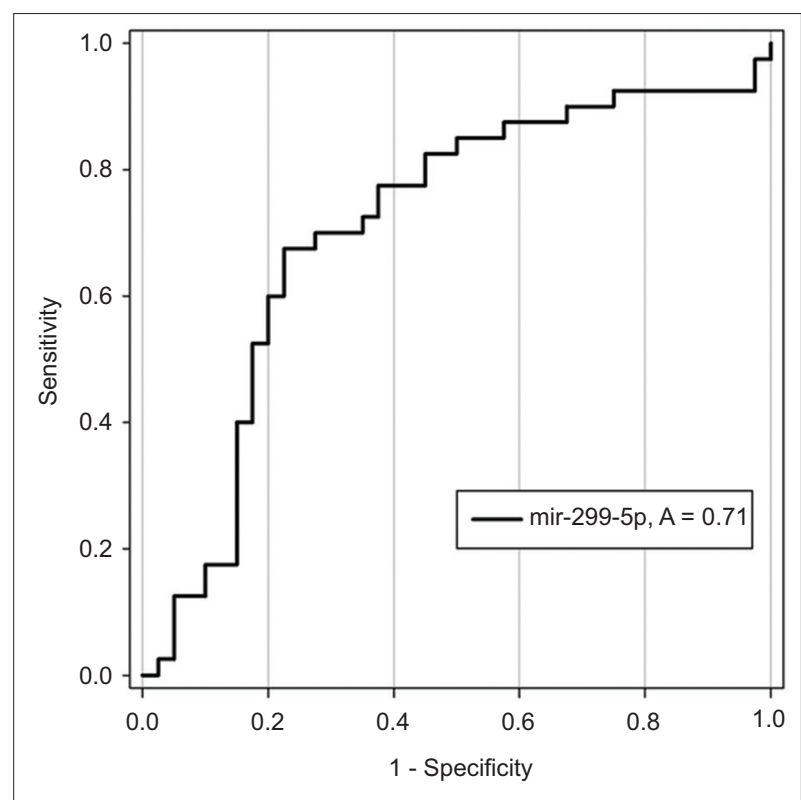

Figure 2 Receiver operating characteristic (ROC) analysis of miR-299-5p as a biomarker in the detection of colorectal cancer. The ROC curve was generated from 40 points with a cutoff value set by SigmaPlot software. The area under the curve was $71 \%$ for miR-299$5 p$, with $68 \%$ sensitivity and $78 \%$ specificity 


\section{Discussion}

It is crucial to improve the recognition of molecular factors that have prognostic and predictive significance in CRC [24]. MicroRNAs have an evident role in the initiation and progression of CRC. However, future research will have to precisely reveal the potential role of microRNA-based classifiers and therapeutics in medicine. A good number of studies have confirmed the potential of miRNAs as predictive/prognostic classifiers for early cancer detection [2]. There are many reports on the effects of miRNAs on oncogenes and tumor suppressor genes [25]. Downregulation of miRNAs is generally observed in human cancers [26]. It should be noted that many miRs have been previously studied in CRC $[22,27,28]$.

The DLK1-DIO3 genomic locus present on chromosome $14 \mathrm{q} 32.31$ is a parentally imprinted region [13]; this region is one of the largest miRNA-containing clusters of the human genome and contains 54 miRNAs [13]. Most imprinted genes play key roles in placental growth and have been implicated in embryonic and developmental abnormalities in the mouse and human [29]. MiRNAs within the DLK1-DIO3 genomic region have been shown to be involved in disease pathogenesis, mainly of cancers. Multiple miRNAs from this cluster potentially target the factor of the Polycomb repressive complex 2 (PRC2), which plays a significant role in the prevention of PRC2 formation; hence, the aforementioned region could remain active in full pluripotent stem cells [13]. MiR-299-5p was found to be downregulated in oral squamous cell carcinoma cell lines [30] and prostate cancer cells [31]. Another study showed that miR299-5p was upregulated in myelodysplastic syndrome [32]. MiR-299-5p was downregulated in metastatic breast cancer patients [33] and high risk neuroblastoma [34]. MiR-299-5p was downregulated in patients with t (11q23)/MLL-rearrangement and upregulated in t (15:17) cytogenetic subtypes [35]. Another study on hepatoma cells showed that hsa-miR-299-5p targeted osteopontin (OPN), which is known to be essential for enhancing proliferation and tumorigenicity [36]. Gain- and loss-of-function experiments revealed that miR-299-5p plays a role in the regulation of hematopoietic progenitor; it may therefore act as miRNA in the differentiation of megakaryoblasts [37]. Research on A549 human non-small cell lung cancer cells indicated that expression of miR-299-5p was upregulated [38].

One study revealed that miR-299-5p regulates OPN, and that increasing the expression of OPN via decreased levels of miR-299-5p plays an important role in enhancing proliferation, tumorigenicity, and the ability to display vasculogenic mimicry of the spheroid formation of breast cancer cells [39]. According to previous research, OPN is a multifunctional cytokine that influences several signaling pathways that are associated with cell proliferation, survival, drug resistance, invasion, stem-like behavior, apoptosis, and metastatic potential [40]. Past reports reveal that estrogen-related receptor $\alpha$ regulates OPN expression in human CRC. OPN is a direct target of estrogen-related receptor $\alpha$, the induction of which could clearly contribute to CRC pathogenesis [41]. OPN in CRC may be a clinical prognostic marker significantly associated with prognosis [42]. OPN appears to regulate motility through interaction with CD44. An increase in OPN results in an increase in the

\section{Summary Box}

\section{What is already known:}

- Colorectal cancer (CRC) is considered as the third most common cause of cancer-related deaths, accounting for $10 \%$ of worldwide cancer incidence and mortality

- The yearly incidence of CRC is expected to increase over the next two decades in developing countries, especially in Asia

- Recent studies in Iran suggest a rapid increase in the incidence of CRC

\section{What the new findings are:}

- MiR-299-5p was significantly downregulated in CRC samples compared to their normal counterparts

- MiR-299-5p expression level may be regarded as a tumor marker for distinguishing CRC from normal tissue

- As a potential predictive biomarker, miR-299-5p can help diagnose CRC

expression of vascular endothelial growth factor [40]. There are mutual interactions between TAM receptors and CD44positive CRC cancer cells via OPN/CD44 [43].

In conclusion, the present study revealed that miR-299-5p was significantly downregulated in CRC samples compared to their normal counterparts. However, the reason for the misregulation of this miRNA is unclear, though a loss of heterozygosity or epigenetic silencing could be responsible. Based on the above findings, miR-299-5p regulates OPN, which is a critical gene in several signaling pathways, especially in cancer. It is clear that more studies on the relationship between miR-299-5p and OPN in CRC may yield better results regarding the therapeutic targets.

The capability of miR-299-5p expression level to function as a tumor marker to distinguish CRC from normal tissue was also determined in the current study, suggesting that this miRNA has a high sensitivity and specificity; therefore, it can be regarded as a tumor marker in diagnosing CRC. However, to determine a more detailed association between these mRNAs and clinicopathological features (e.g. age, sex, tumor grade, and tumor location), other studies with larger sample sizes need to be conducted.

\section{Acknowledgments}

We would like to thank the patients, staff, and nurses in the Endoscopy and the Pathology departments of Tabriz Imam Reza hospital who kindly helped us conduct this study. 


\section{References}

1. Ansari R, Mahdavinia $\mathrm{M}$, Sadjadi $\mathrm{A}$, et al. Incidence and age distribution of colorectal cancer in Iran: results of a populationbased cancer registry. Cancer Lett 2006;240:143-147.

2. Schetter AJ, Okayama H, Harris CC. The role of microRNAs in colorectal cancer. Cancer J 2012;18:244-252.

3. Rezaianzadeh A, Safarpour AR, Marzban M, Mohaghegh A. A systematic review over the incidence of colorectal cancer in Iran. Ann Colorectal Res 2015;3:e25724.

4. Sung JJ, Lau JY, Goh KL, Leung WK; Asia Pacific Working Group on Colorectal Cancer. Increasing incidence of colorectal cancer in Asia: implications for screening. Lancet Oncol 2005;6:871-876.

5. Siegel RL, Miller KD, Jemal A. Cancer statistics, 2016. CA Cancer J Clin 2016;66:7-30.

6. Dolatkhah R, Somi MH, Bonyadi MJ, et al. Colorectal cancer in Iran: molecular epidemiology and screening strategies. J Cancer Epidemiol 2015;2015:643020.

7. Moghimi-Dehkordi B, Safaee A, Zali MR. Prognostic factors in 1,138 Iranian colorectal cancer patients. Int J Colorectal Dis 2008;23:683688.

8. Somi MH, Golzari M, Farhang S, et al. Gastrointestinal cancer incidence in East Azerbaijan, Iran: update on 5 year incidence and trends. Asian Pac J Cancer Prev 2014;15:3945-3949.

9. Arnold M, Sierra MS, Laversanne M et al. Global patterns and trends in colorectal cancer incidence and mortality. Gut 2016: gutjnl-2015-310912.

10. Lee RC, Feinbaum RL, Ambros V. The C. elegans heterochronic gene lin-4 encodes small RNAs with antisense complementarity to lin- 14 . Cell 1993;75:843-854.

11. Chang KH, Miller N, Kheirelseid EA, et al. MicroRNA signature analysis in colorectal cancer: identification of expression profiles in stage II tumors associated with aggressive disease. Int J Colorectal Dis 2011;26:1415-1422.

12. Faltejskova P, Svoboda M, Srutova K, et al. Identification and functional screening of microRNAs highly deregulated in colorectal cancer. J Cell Mol Med 2012;16:2655-2666.

13. Benetatos L, Hatzimichael E, Londin E, et al. The microRNAs within the DLK1-DIO3 genomic region: involvement in disease pathogenesis. Cell Mol Life Sci 2013;70:795-814.

14. Volinia S, Calin GA, Liu CG, et al. A microRNA expression signature of human solid tumors defines cancer gene targets. Proc Natl Acad Sci U S A 2006;103:2257-2261.

15. Lin SP, Youngson N, Takada S, et al. Asymmetric regulation of imprinting on the maternal and paternal chromosomes at the Dlk1-Gtl2 imprinted cluster on mouse chromosome 12. Nat Genet 2003;35:97-102.

16. Stadtfeld M, Apostolou E, Akutsu H, et al. Aberrant silencing of imprinted genes on chromosome $12 \mathrm{qF} 1$ in mouse induced pluripotent stem cells. Nature 2010;465:175-181.

17. Haller F, von Heydebreck A, Zhang JD, et al. Localization- and mutation-dependent microRNA (miRNA) expression signatures in gastrointestinal stromal tumours (GISTs), with a cluster of coexpressed miRNAs located at 14q32.31. J Pathol 2010;220:71-86.

18. Bartel DP. MicroRNAs: target recognition and regulatory functions. Cell 2009;136:215-233.

19. Costa FF, Bischof JM, Vanin EF, et al. Identification of microRNAs as potential prognostic markers in ependymoma. PLoS One 2011;6:e25114.

20. Gattolliat CH, Thomas L, Ciafrè SA, et al. Expression of miR-487b and miR-410 encoded by $14 \mathrm{q} 32.31$ locus is a prognostic marker in neuroblastoma. Br J Cancer 2011;105:1352-1361.

21. Thayanithy V, Sarver AL, Kartha RV, et al. Perturbation of $14 \mathrm{q} 32$ miRNAs-cMYC gene network in osteosarcoma. Bone 2012;50:171-181.

22. D’Angelo E, Fassan M, Maretto I, et al. Serum miR-125b is a noninvasive predictive biomarker of the pre-operative chemoradiotherapy responsiveness in patients with rectal adenocarcinoma. Oncotarget 2016;7:28647-28657.

23. da Rocha ST, Edwards CA, Ito M, Ogata T, Ferguson-Smith AC. Genomic imprinting at the mammalian Dlk1-Dio3 domain. Trends Genet 2008;24:306-316.

24. Alimov A, Sundelin B, Wang N, Larsson C, Bergerheim U. Loss of $14 \mathrm{q} 31-\mathrm{q} 32.2$ in renal cell carcinoma is associated with high malignancy grade and poor survival. Int J Oncol 2004;25:179-185.

25. Wang Y, Chen M, Tao Z, Hua Q, Chen S, Xiao B. Identification of predictive biomarkers for early diagnosis of larynx carcinoma based on microRNA expression data. Cancer Genet 2013;206:340-346.

26. Melo SA, Esteller M. Dysregulation of microRNAs in cancer: playing with fire. FEBS Lett 2011;585:2087-2099.

27. Perilli L, Vicentini C, Agostini M, et al. Circulating miR-182 is a biomarker of colorectal adenocarcinoma progression. Oncotarget 2014;5:6611-6619.

28. Orang AV, Safaralizadeh R, Hosseinpour Feizi MA, Somi MH. Diagnostic and prognostic value of miR-205 in colorectal cancer. Asian Pac J Cancer Prev 2014;15:4033-4037.

29. Seitz H, Royo H, Bortolin ML, Lin SP, Ferguson-Smith AC, Cavaillé J. A large imprinted microRNA gene cluster at the mouse Dlk1-Gtl2 domain. Genome Res 2004;14:1741-1748.

30. Kozaki K, Imoto I, Mogi S, Omura K, Inazawa J. Exploration of tumor-suppressive microRNAs silenced by DNA hypermethylation in oral cancer. Cancer Res 2008;68:2094-2105.

31. Formosa A, Markert E, Lena A, et al. MicroRNAs, miR-154, miR299-5p, miR-376a, miR-376c, miR-377, miR-381, miR-487b, miR-485-3p, miR-495 and miR-654-3p, mapped to the $14 q 32.31$ locus, regulate proliferation, apoptosis, migration and invasion in metastatic prostate cancer cells. Oncogene 2014;33:5173-5182.

32. Dostalova Merkerova M, Krejcik Z, Votavova H, et al. Distinctive microRNA expression profiles in CD34+ bone marrow cells from patients with myelodysplastic syndrome. Eur J Hum Genet 2011;19:313-319.

33. McGuire A, Brown JA, Kerin MJ. Metastatic breast cancer: the potential of miRNA for diagnosis and treatment monitoring. Cancer Metastasis Rev 2015;34:145-155.

34. Mei H, Lin ZY, Tong QS. The roles of microRNAs in neuroblastoma. World J Pediatr 2014;10:10-16.

35. Marcucci G, Mrózek K, Radmacher MD, Garzon R, Bloomfield CD. The prognostic and functional role of microRNAs in acute myeloid leukemia. Blood 2011;117:1121-1129.

36. Jin JC, Jin XL, Zhang X, Piao YS, Liu SP. Effect of OSW-1 on microRNA expression profiles of hepatoma cells and functions of novel microRNAs. Mol Med Rep 2013;7:1831-1837.

37. Tenedini E, Roncaglia E, Ferrari F, et al. Integrated analysis of microRNA and mRNA expression profiles in physiological myelopoiesis: role of hsa-mir-299-5p in CD34+ progenitor cells commitment. Cell Death Dis 2010;1:e28.

38. Bae S, Lee EM, Cha HJ, et al. Resveratrol alters microRNA expression profiles in A549 human non-small cell lung cancer cells. Mol Cells 2011;32:243-249.

39. Shevde LA, Metge BJ, Mitra A, et al. Spheroid-forming subpopulation of breast cancer cells demonstrates vasculogenic mimicry via hsamiR-299-5p regulated de novo expression of osteopontin. J Cell Mol Med 2010;14:1693-1706.

40. Irby R, McCarthy S, Yeatman T. Osteopontin regulates multiple functions contributing to human colon cancer development and progression. Clinical Exp Metastasis 2004;21:515-523.

41. Boudjadi S, Bernatchez G, Beaulieu JF, Carrier JC. Control of the human osteopontin promoter by ERRa in colorectal cancer. Am J Pathol 2013;183:266-276.

42. Likui W, Hong W, Shuwen Z. Clinical significance of the upregulated osteopontin mRNA expression in human colorectal cancer. J Gastrointest Surg 2010;14:74-81.

43. Shevde LA, Samant RS. Role of osteopontin in the pathophysiology of cancer. Matrix Biol 2014;37:131-141. 